\title{
Um estudo sobre a (re)construção de objetos do discurso em processos de retextualização na perspectiva do ensino
}

\author{
A study on the (re)construction of discourse objects in re- \\ textualization processes from the perspective of teaching
}

\author{
Wellington Gomes de Souza* \\ Lidiane de Morais Diógenes Bezerra**
}

RESUMO: Este artigo baseia-se na relação entre processos de retextualização e processos referenciais na perspectiva do ensino. Nesse contexto, o objetivo é analisar a construção de referentes transpostos entre gêneros, na caracterização do que se denomina anáfora intertextual. Constituem-se objeto de estudo produções textuais de alunos do ensino médio oriundas de práticas de transformação textual. Fundamentam esta abordagem autores como Marcuschi (2001), Dell'Isola (2007), Mondada e Dubois (1995) e Custódio Filho (2015). A pesquisa é de natureza aplicada e orientada por levantamento bibliográfico. Os resultados apontam para a importância do uso da referenciação e da retextualização como estratégias de construção textual de sentidos e, portanto, são de grande valia para conduzir o trabalho com textos em sala de aula.

PALAVRAS-CHAVE: referenciação; retextualização; anáfora intertextual; ensino.

ABSTRACT: This article is based on the relationship between retextualization processes and referential processes in the teaching perspective. In this context, the objective is to analyze the construction of referents transposed between genres, in the characterization of what is called intertextual anaphor. The textual productions of high school students from textual transformation practices are object of this study. This approach is based on authors such as Marcuschi (2001), Dell'Isola (2007), Mondada and Dubois (1995) and Custódio Filho (2015). This research is applied and guided by a bibliographic survey. The results point to the importance of using referencing and retextualization as strategies for textual construction of meanings. Thus, they have great value to conduct the work with texts in the classroom.

KEYWORDS: referencing; retextualization; intertextual anaphor; teaching.

\footnotetext{
* Professor da Rede Estadual de Educação do Ceará. Doutorando do Programa de Pós-Graduação em Letras (PPGL) da Universidade do Estado do Rio Grande do Norte (UERN). E-mail: wellington83souza@gmail.com. ORCID: https://orcid.org/oooo-0oo2-9751-9030.

** Professora Doutora da Universidade do Estado do Rio Grande do Norte (UERN), Campus Avançado "Profa. Maria Elisa de Albuquerque Maia" (CAMEAM). Doutora em Estudos da Linguagem pela UFRN. lidmoraisb@gmail.com. ORCID: https://orcid.org/oooo-0002-95695567.
} 


\section{Introdução}

Os estudos realizados no cerne da Linguística Textual (LT) oferecem insumos diversos para a construção de uma visão holística sobre o processo de produção de textos. Assim, no rol dos objetos de análise que são contemplados pela LT, elegemos para escopo desta abordagem a referenciação.

Nesse contexto, assentamos esta discussão nas perspectivas de estudo sobre o tema, as quais suscitam uma gama de pensamentos acerca dos procedimentos para a abordagem desse fenômeno, bem como para a ampliação de seu campo de análise. É o que podemos observar, por exemplo, quando tratamos da relação dos processos referenciais com a intertextualidade, a interdiscursividade, entre outros percursos teóricos, em pesquisas que promovem a interface desse fenômeno com outras áreas de conhecimento no tocante à linguagem.

Tomando como base os processos referenciais anafóricos, podemos observar como perspectiva de ampliação a possibilidade de abordagem intertextual, com a qual nos ocuparemos mais adiante. De maneira geral, as anáforas são analisadas a partir de um dado cotexto, em uma delimitação intratextual. Para além disso, todavia, entendemos ser perceptível o caráter intertextual das anáforas, embasados, por exemplo, nas discussões de Custódio Filho (2015). Isso mostra, a nosso ver, como há terreno para discussão sobre o fenômeno da referenciação.

No âmbito do ensino, a análise dos processos referenciais oferece insumos importantes para a abordagem textual. Para sustentar essa ideia, podemos mencionar o fato de que é possível elaborar atividades de leitura e de escrita com base em aspectos da referenciação, os quais discutiremos em nossa empreitada, como a negociação de sentidos, a importância da recategorização para o desenvolvimento argumentativo e das relações anafóricas para a progressão textual, conforme vemos em Cavalcante, Custódio Filho e Brito (2014). Assim, o uso desse tipo de estratégia em contextos de ensino possibilita aos discentes o contato com novas perspectivas de produção textual. 
A partir do contexto dialógico que transpõe a referenciação, podemos associá-la, a nosso ver, à estratégia de retextualização, pois esse processo consiste na transformação textual, por meio de um trabalho de refacção ou de reescrita de textos (DELL'ISOLA, 2007), que pode ocorrer com a mudança de gênero ou não, com a possibilidade de alteração de registro, entre outras formas, algo que reflete na (re)construção de referentes de um texto. A essa reconstrução referencial, que pode perpassar determinadas materialidades linguísticas, denomina-se referenciação intertextual (CUSTÓDIO FILHO, 2015).

Vale dizer que, no âmbito da relação entre essas duas estratégias textuais, há estudos que discorrem sobre a recategorização de objetos de discurso na passagem do texto-base para o texto retextualizado, como vemos em Coelho (2013) e Barbosa (2014); ou, ainda, na correlação existente entre os dois processos, na produção escrita no contexto acadêmico, conforme o que se apresenta em Mata (2008). Entretanto, parece-nos lacunar a perspectiva intertextual dos processos anafóricos que permeia essa relação, sobretudo voltada para o ensino de textos na educação básica.

Diante dessas considerações, nosso objetivo é analisar a construção de objetos de discurso passados de um gênero textual a outro, a partir de processos de retextualização, na caracterização das anáforas intertextuais. Nesse sentido, pretendemos discutir, também, a produção de sentidos ancorada na (re)categorização de referentes para esse tipo anafórico, tomando como objeto de análise textos produzidos por alunos da educação básica, na defesa de que esse tipo de estratégia contribui para o ensino de gêneros.

Para fundamentar esta proposta, recorremos, basicamente, a Marcuschi (2001) e Dell'Isola (2007), como referenciais no âmbito da retextualização; e Mondada e Dubois (1995), Cavalcante, Custódio Filho e Brito (2014) e Custódio Filho (2015), que tratam de aspectos concernentes à referenciação e seus desdobramentos.

Como procedimentos para aplicação, recorremos à análise de textos produzidos por alunos do ensino médio desenvolvidos mediante processos de retextualização da escrita para a escrita, na transformação de um conto e de um poema, ambos retextualizados para o gênero notícia. $O$ trabalho com esse novo gênero centrou-se na discussão sobre a construção dos objetos de discurso, que 
foram transpostos de um gênero textual para outro, algo de suma importância para a verificação da presença de anáforas intertextuais e para o processo de produção textual desenvolvido pelos discentes.

O desenvolvimento dessas atividades ocorreu mediante os procedimentos de retextualização apresentados por Dell'Isola (2007), que vão da leitura de um texto até a reescrita de outro. Os alunos produziram os textos em aulas de língua portuguesa, sob o intermédio do professor-pesquisador.

Salientamos que, para esta abordagem, estamos considerando texto como um evento sociocomunicativo, pautado na interação entre interlocutores; gênero textual como práticas comunicativas que se constroem por meio de processos interacionais dos quais participam os sujeitos; e a materialidade linguística como o que se apresenta na superfície textual, isto é, no cotexto (KOCH; ELIAS, 2017).

Um ponto de contribuição deste artigo está relacionado à perspectiva de transposição de objetos de discurso, pois a tendência é ter como escopo a construção referencial em uma determinada superfície textual. Para além dessa visão, a análise proposta centra-se na possibilidade de passagem de referentes de um texto para outro, em um processo de (re)construção dos referentes intertextualmente.

Nossa abordagem, portanto, consiste em uma ampliação no campo de estudos dos processos referenciais anafóricos por duas razões: (i) transpõe as barreiras de um determinado gênero, na tendência mais habitual de estudos sobre a anáfora, centrada na perspectiva intratextual; (ii) tem como base os estudos realizados por Custódio Filho (2015), propondo uma associação da referenciação com os processos de retextualização, algo que vai além da discussão do autor, que fora centrada em uma continuidade de gênero, e não na transformação, que é outra possibilidade para tratar desse procedimento. 


\section{Estratégias de retextualização: o trabalho de transformação textual e a construção de sentidos}

A retextualização consiste em uma estratégia de produção textual que envolve uma série de fatores inerentes ao uso da linguagem, os quais operam sobre o código e sobre o sentido, como um processo de transformação de modalidades textuais por meio de refacção ou de reescrita (DELL'ISOLA, 2007); além de englobar aspectos linguísticos, textuais, discursivos e cognitivos (MARCUSCHI, 2001), que podem culminar na mudança de gênero ou de modalidade, ou serem operadas sem que essa mudança necessariamente ocorra. Seu desenvolvimento suscita algumas operações que influenciam tanto a transformação do cotexto, quanto do contexto $^{9}$, direcionando a produção de sentidos e o trânsito entre as diversas modalidades textuais.

Para o desenvolvimento de atividades dessa natureza, há a ativação de vários conhecimentos que subsidiam o trabalho de produção e de recepção dos textos que compõem os processos de retextualização. Nesse sentido, é importante ressaltar que, para a nossa perspectiva de abordagem, há, ao menos, dois gêneros textuais envolvidos em tais procedimentos: um que consistirá no texto-base, matéria-prima para a exploração das possibilidades de trabalho nessa perspectiva de transformação; e outro que será o texto-alvo, resultado da retextualização, que tem um caminho traçado, conforme Dell'Isola (2007), pelas etapas de leitura, compreensão, reconhecimento do gênero, retextualização propriamente dita, conferência, identificação do novo texto e reescrita.

Diante desses fatores, vale dizer que a escrita, nessa perspectiva, requer conhecimentos lexicais, de mundo, de estrutura textual, bem como a ativação de modelos cognitivos que, segundo Koch e Elias (2017), traduzem-se em conhecimentos linguísticos, enciclopédicos, textuais e interacionais que permeiam a adequação concernente às diversas situações comunicativas das

\footnotetext{
9 Estamos tratando cotexto como a superfície textual, de onde partem as possibilidades de produção de sentidos no tocante à referenciação, e contexto como os aspectos diversos que rodeiam essa materialidade, como os sociocognitivos (KOCH, 2009).
} 
quais os interlocutores participam. Assim, o trabalho com a retextualização no contexto escolar pode promover a produção textual de modo mais exitoso, tendo em vista que é realizado mediante a ativação desses conhecimentos.

No âmbito da abordagem das autoras, podemos dizer, também, que a retextualização reivindica a competência metagenérica para a sua realização, visto que o conhecimento sobre os gêneros é necessário para a transformação textual. Ou seja, o êxito desse processo de produção escrita perpassa pelo domínio dos estudantes acerca dos gêneros textuais, levando em consideração suas práticas comunicativas e o conhecimento de mundo que detêm para produzir sentidos.

Salientamos que o entendimento sobre gêneros, em nossa perspectiva de análise, está centrado no seu enquadramento como categoria textual que circula na sociedade, servindo como instrumento de interação para práticas comunicativas, isto é, ferramenta de ação social presente em diversos domínios discursivos (TRAVAGLIA, 2017). Nesse sentido, vale ressaltar que a produção textual, a partir de procedimentos de retextualização, embora ocorra de modo didático, é realizada com base em situações comunicativas das quais os alunos são conhecedores.

Encontramos aporte, ainda, em Marcuschi (2008), que apresenta a noção de gênero como entidade que engloba os textos materializados em situações comunicativas recorrentes em nosso dia a dia e como forma de ação social comunicativa. Nas palavras do autor, “os gêneros são entidades empíricas em situações comunicativas e se expressam em designações diversas, constituindo, em princípio, listagens abertas” (MARCUSCHI, 2008, p. 155).

Assim, é possível advogar que a abordagem sobre gêneros com base no desenvolvimento dos processos de retextualização amplia os olhares sobre determinado gênero, tanto a respeito de sua materialidade, quanto no que se refere aos aspectos extralinguísticos. Dessa forma, se nos valermos da metáfora do iceberg, citada por Koch (2010), e entendermos a sua ponta como o cotexto que, a nosso ver, poderia estar relacionado ao conhecimento linguístico, ou seja, à materialidade textual, teríamos, com a retextualização, condição de explorar além da superfície textual. 
Por isso, no centro do trabalho com a escrita, é necessário o reconhecimento do processo interativo, dialógico, de natureza sociocognitiva, que permeia o desenvolvimento dessa tecnologia. Nesse contexto, é preciso criar caminhos que possibilitem a percepção da interação entre a produção escrita e o mundo real do qual o aluno faz parte. Em outras palavras, necessita-se de uma abordagem sobre texto que seja pautada por aspectos consistentes na esfera comunicativa na qual os estudantes estão inseridos. Para Dell'Isola (2007), devemos concentrar as ações pedagógicas na compreensão das práticas linguageiras no meio social. Desse modo, a autora reitera que:

os profissionais da linguagem precisam levar os alunos a compreender e procurar explicar como se manifestam os diferentes gêneros textuais. A identidade, os relacionamentos e o conhecimento dos seres humanos são determinados pelos gêneros textuais a que estão expostos, que produzem e consomem. O estudo dos gêneros possibilita a exploração de algumas regularidades nas esferas sociais em que eles são utilizados. (DELL'ISOLA, 2007, p. 24)

Portanto, temos, na retextualização, procedimentos plausíveis para promover a interação textual em atividades de produção escrita. Nisso, vamos além das questões meramente estruturais dos gêneros, observando outros aspectos atinentes a eles, como o seu funcionamento na esfera social, seu espaço de interação, construção e reconstrução de sentidos.

Vale dizer, também, que o desenvolvimento de processos dessa natureza pode caminhar por diversas possibilidades, conforme apresentamos no Quadro 1.

Quadro 1 - Possibilidades de retextualização

\begin{tabular}{|ccccc|}
\hline Fala & $\longrightarrow$ & Escrita (entrevista oral & $\longrightarrow$ & entrevista impressa) \\
2 Fala & $\longrightarrow$ & Fala (conferência & $\longrightarrow$ & tradução simultânea) \\
3 Escrita & $\longrightarrow$ & Fala (texto escrito & $\longrightarrow$ & exposição oral) \\
4 Escrita & $\longrightarrow$ & Escrita (texto escrito & $\longrightarrow$ & resumo escrito) \\
\hline
\end{tabular}

Para além desse quadro, podemos citar outras possibilidades que estão relacionadas à visão de texto que transpõe o código verbal. De acordo com Cavalcante e Custódio Filho (2010), por exemplo, o estatuto do texto ramificou- 
se ao longo dos estudos linguísticos, ultrapassando, assim, os limites da superfície textual, sobretudo para dar conta dos sentidos produzidos que, apesar de oriundos do contexto, perpassam outras instâncias textuais, como ocorre nos casos de multimodalidade. Com isso, as setas do Quadro 1 podem indicar outras direções, pois a dinâmica de processamento textual leva os interlocutores a vários caminhos para a construção de sentidos.

Diante dessas possibilidades, delimitamos a retextualização como um processo de transformação textual, seja de um gênero textual para outro, seja de uma modalidade para outra, cujas operações são variadas, a depender das situações comunicativas específicas nos contextos de uso da linguagem. É importante ressaltar que não estamos desconsiderando o fato de que a retextualização pode ser realizada de outras formas, como àquelas que ocorrem no seio de uma mesma modalidade ou de um mesmo gênero, com a mudança de registro, por exemplo, como vemos em Marcuschi (2001).

Não obstante às diversas situações de retextualização, nosso escopo é a abordagem sobre a transformação textual da escrita para a escrita, pois, nessa modalidade, entendemos que se concentram várias dificuldades por parte dos discentes que podem ser minimizadas, mediante o desenvolvimento dos processos de retextualização.

Por isso, vemos a retextualização como uma possibilidade de fomentar a prática da produção escrita. Vale ressaltar que, em atividades dessa natureza, há condições de desenvolver, ainda, habilidades de leitura, pois o trabalho nessa perspectiva é um aspecto imprescindível para o desenvolvimento exitoso desses processos. A esse respeito, Marcuschi (2001, p. 47, grifos do autor) diz o seguinte:

Há nestas atividades de retextualização um aspecto geralmente ignorado e de uma importância imensa. Pois para dizer de outro modo, em outra modalidade ou em outro gênero o que foi dito ou escrito por alguém, devo inevitavelmente compreender o que foi que esse alguém disse ou quis dizer. Portanto, antes de qualquer atividade de transformação textual, ocorre uma atividade cognitiva denominada compreensã̃o.

Às palavras do autor, associamos a ideia de que a produção escrita, orientada pela leitura e com vistas à transformação textual, consiste em uma atividade bastante produtiva, conforme nos aponta Dell'Isola (2007). Portanto, 
defendemos a importância da aplicação de atividades de retextualização para que possamos criar novos caminhos para o trabalho com o texto escrito no contexto escolar.

Diante dessa abordagem, vemos o ensejo para a promoção da interface entre o desenvolvimento das atividades de retextualização e os processos referenciais. Isso se deve ao seguinte: assim como podemos observar a condução de um referente no seio de um texto-base, sua ativação, reativação, as (re)categorizações provenientes de sua retomada, entre outros aspectos que concorrem para a (re)construção de um objeto de discurso, podemos dizer que isso se dá na produção de um texto-alvo. Assim, é perceptível que há uma retomada inicial de um objeto de discurso de um texto para sua reconstrução e adequação em outro contexto comunicativo.

Por isso, com base em Custódio Filho (2015), podemos levantar ao menos dois pontos acerca dessa relação entre uma e outra estratégia: (i) a construção de objetos de discurso, por meio da retextualização, consiste na transposição de referentes de um texto para outro, adequando-se à recontextualização do textoalvo, o que pode variar a depender do gênero textual almejado para a transformação; (ii) esse tipo de procedimento caracteriza o que o autor chama de anáfora intertextual, tendo em vista a retomada de um referente de um determinado cotexto e sua adequação a uma nova situação comunicativa. É preciso, então, tratarmos de algumas questões concernentes à referenciação para darmos conta da análise proposta neste artigo.

\section{Referenciação: aspectos gerais}

Desde o advento dos estudos acerca da referenciação, com a abordagem precursora de Mondada e Dubois (1995), esse fenômeno vem sendo bastante produtivo para o trabalho com o processamento textual. Isso porque as pesquisas dão conta, de modo geral, de uma série de ocorrências em que os processos referenciais contribuem para a construção de sentidos de um texto, seja em sua produção, seja em sua recepção. 


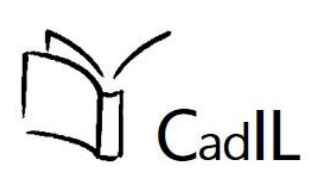

Desse modo, quanto mais se coteja o fenômeno em pauta, mais se alastra o campo para discussão sobre ele, o que é positivo para a ampliação do horizonte de estudo dos processos referenciais. Nessa perspectiva, podemos citar o caso dos processos referenciais anafóricos, que, em linhas gerais, promovem continuidades de objetos de discurso pautadas em sua retomada, mediante uma relação de ancoragem.

Vale dizer que, nesse contexto de amplitude, os estudos sobre a referência textual, além de se pautarem em uma perspectiva centrada na semântica lógica, que via o discurso enquanto correspondente ideal para os objetos de mundo, passaram a considerar uma perspectiva sociocognitiva e interacional, voltada para a ideia de que os referentes de um texto/discurso constroem-se e reconstroem-se no curso das atividades discursivas, nos variados contextos, algo que é característico dos processos referenciais, conforme preconizaram Mondada e Dubois (1995).

Segundo as autoras, é problemática a paridade relativa ao modelo estabelecido para discretizar a correspondência entre palavras e objetos do mundo exterior ao texto, sobretudo pelo seu caráter unívoco que converge para uma estabilidade improvável entre texto e mundo. Essa modelação não se enquadra, por exemplo, na perspectiva sociocognitiva interacional, que rege os estudos da Linguística Textual em algumas de suas variadas abordagens, tendo em vista o caráter dialógico do texto que, nas palavras de Koch (2009), é lugar de interação onde os interlocutores atuam como construtores sociais do mundo através da linguagem.

Por isso, a noção de referência no cerne de uma semântica abstrata é, certamente, simplista sob a ótica interacionista, social e discursiva, que orienta a perspectiva dos estudos da linguagem que adotamos nesta discussão. Assim, a relação entre palavras e mundo exterior envolve outros aspectos, como podemos observar em Koch (2009, p. 32):

As abordagens interacionistas consideram a linguagem uma ação compartilhada que percorre um duplo percurso na relação sujeito/realidade e exerce dupla função em relação ao desenvolvimento cognitivo: intercognitivo [sujeito/mundo] e intracognitivo [linguagem e outros processos cognitivos]. 


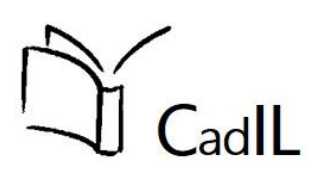

Com base no que expõe a autora, a relação entre texto e mundo não condiz com a ideia de estabilidade, haja vista consistir em um estágio processual, cuja característica marcante é a instabilidade dos objetos de discurso do texto. Ressaltemos que Mondada e Dubois (1995), por exemplo, apontam para essa instabilidade ao dizerem que esses objetos não são preexistentes, mas elaborados e transformados a partir dos contextos. Nesse sentido, dizem as autoras, a instabilidade é manifestada nas atividades discursivas, entre outros aspectos, pelas configurações dos referentes.

Diante desse cenário, portanto, a referenciação remete-nos ao estudo das categorizações consideradas, de acordo com Mondada e Dubois (1995), como processos oriundos das relações individuais e sociais, inter e intracognitivas, presentes na complexidade que envolve as ações de linguagem. Em síntese, a referenciação consiste na "construção sociocognitivo-discursiva de objetos de discurso reveladores de versões da realidade e estabelecidos mediante processos de negociação" (CAVALCANTE; CUSTÓDIO FILHO; BRITO, 2014, p. 41).

Vale dizer, assim, que esse fenômeno não consiste apenas em pontuar a relação entre segmentos linguísticos na superfície textual, mas, conforme aponta Koch (2009), atua na ativação da memória discursiva dos interlocutores, envolvendo aspectos semânticos que vão além da observância do estatuto linguístico inerente a um evento discursivo, como pode ser observado pelo domínio extralinguístico da linguagem, por exemplo.

\subsection{Anáforas e a perspectiva do ensino}

Diante do quadro geral sobre a referenciação, temos três categorias que norteiam os estudos acerca dos processos referenciais: a introdução referencial, a anáfora e a dêixis. Ancorados em Cavalcante, Custódio Filho e Brito (2014), podemos dizer, sucintamente, que a introdução referencial diz respeito à presença de um referente novo no texto; a anáfora caracteriza-se, basicamente, pela continuidade proporcionada a uma referência, direta ou indiretamente; e a dêixis situa os participantes do ato comunicativo, estabelecendo relação entre o cotexto e a situação enunciativa. 
Dessas categorias, selecionamos como escopo o estudo sobre os processos referenciais anafóricos, em atividades de retextualização. Vale dizer, nesse sentido, que a ocorrência de anáforas nos textos nos conduz para uma riqueza de classificação que vem sendo discutida e ampliada no decorrer dos estudos sobre referenciação.

Das várias concepções classificatórias que são elencadas, podemos mencionar a de Apothéloz (1995), que subdivide as anáforas correferenciais em dois tipos: fiéis e infiéis, sendo que o primeiro tipo se refere à retomada de um referente por um termo anaforizante que possui o mesmo núcleo presente na introdução referencial; já o segundo tipo apresenta um nome-núcleo diferente da forma inicial do objeto do discurso.

Em uma perspectiva ampliada, Cavalcante (2003) apresenta dois grandes grupos de anáforas, com seus respectivos desdobramentos: anáforas com retomada e anáforas sem retomada. No primeiro grupo, temos as anáforas correferenciais, pautadas em processos de remissão, de reiteração e de recategorização de um mesmo referente, ou seja, consistem na retomada de objetos de discurso de modo direto no texto. Já no segundo grupo, a autora apresenta as anáforas indiretas e as encapsuladoras, que podem ser observadas sem que apontem, explicitamente, para um referente do cotexto, podendo ser estabelecidas através de inferências ou da recuperação de porções textuais, por exemplo ${ }^{10}$.

Para a autora, as anáforas consistem em continuidades referenciais, conforme vimos acima no que se refere à conceituação dessa categoria, o que as diferencia das introduções referenciais. Com esse papel, as anáforas são responsáveis, de modo geral, pela recategorização, pelo encapsulamento dos objetos de discurso, entre outros aspectos inerentes ao curso comunicativo.

Para além dessas classificações dos processos referenciais anafóricos, chama-nos atenção a ideia de referenciação intertextual, visto que apresenta uma

\footnotetext{
10 Em Cavalcante (2003), há um detalhamento dessa classificação que, por uma questão de economia textual, não será apresentado neste artigo. A menção à proposta classificatória da autora é feita com o intento de observar que não se trata da possibilidade de também considerar as anáforas intertextuais, tendo em vista o foco no caráter intratextual desse tipo de retomada.
} 
possibilidade diferente de observar as anáforas em relação às propostas de Apothéloz (1995) e Cavalcante (2003).

Com um direcionamento diferente de análise, Custódio Filho (2015) advoga a favor das anáforas intertextuais, com base na ideia de que os referentes textuais podem transitar entre gêneros, bem como podem ser transpostos de uma materialidade linguística a outra. Nesse caso, temos uma relação anafórica que se amplia em relação àquelas já citadas. Para o autor, a pauta sobre esse tipo de anáfora é justificada pela interação entre textos de diversas naturezas: com interrupção, sem interrupção, em textos de maior ou menor extensão, além do caráter solidário presente em uma cadeia de textos, em que também há a retomada de objetos de discurso. Assim, promove uma abordagem que consiste na análise de referentes que não se limitam a uma materialidade textual, isto é, a um cotexto, como é o caso das produções inerentes a séries televisivas e dos textos literários escritos em volumes, que são seu objeto de estudo.

Com base no que vemos em Custódio Filho (2015), entendemos que há a possibilidade de abordagem na perspectiva do ensino, buscando fortalecer o uso dos recursos referenciais no âmbito escolar. Dessa forma, a ideia de transposição de um objeto de discurso entre textos pertencentes a gêneros diferentes contribui para o processo de produção textual de estudantes da educação básica, conforme mostraremos mais adiante. Desse modo, os mesmos processos de negociação, reelaboração e instabilidade que caracterizam o referente em uma dada superfície textual ocorrem também na interação entre textos, seja pela referenciação anafórica, seja pela intertextualidade clássica da literatura, explícita ou implícita.

Ressaltemos, ainda, que, em um contexto escolar, é possível explorar aspectos concernentes à referenciação, visto que os discentes têm capacidades cognitivas diversas para categorizar e recategorizar referentes textuais, a partir de um processo interacional de trabalho com textos. Nessa empreitada, vale salientar a abordagem realizada por Cavalcante, Custódio Filho e Brito (2014), na defesa da ideia de que os insumos relacionados aos processos referenciais consistem em recursos bastante úteis para a construção da argumentação.

Segundo os autores, os processos referenciais cumprem funções argumentativas que podem ser associadas a outras funções que se fazem presentes nos gêneros textuais e atuam a serviço da argumentação. Com base 
nisso, podemos observar, por exemplo, que a manutenção dos objetos de discurso, no percurso de uma produção de texto, além de promover a progressão textual, consiste em um viés argumentativo para a construção de sentidos, pois as escolhas para a reativação de um referente direcionam para o sentido pretendido pelo enunciador.

De acordo com Cortez e Koch (2013), o desenvolvimento de objetos de discurso que ocorrem em determinado gênero textual permite a percepção de uma orientação argumentativa, que é peculiar ao locutor-enunciador, marcando o ponto de vista desse sujeito. Nessa mesma esteira, Koch (2001) diz que as expressões referenciais são multifuncionais e, por terem esse caráter, também contribuem para a percepção de direções argumentativas, mediante o contato com as facetas inerentes aos objetos de discurso.

Por fim, é importante validar o caráter cognitivo que permeia a ação linguística, pois é isso que caracteriza a natureza de instabilidade do referente, algo que, no contexto escolar, por exemplo, não pode ser visto como inadequado, posto que faz parte do processo interativo. Em outras palavras, é preciso fortalecer a ideia de:

levar em conta tais instabilidades desde que se pare de tratar a variabilidade como um "erro" ou como uma contradição em relação às etiquetas que serão mais "verdadeiras" que outras ou que reenviarão aos objetos reais. (MONDADA; DUBOIS, 1995, p. 26)

Todas essas questões pertinentes aos processos de construção referencial podem caminhar pelo terreno da retextualização. Por isso, buscaremos analisar os aspectos atinentes a esse tipo de relação na produção textual, a fim de defender esse diálogo entre as duas estratégias como recurso viável para o trabalho em sala de aula.

\section{0 texto anaforizante: a migração de objetos de discurso}

A nossa defesa, acerca da relação entre processos referenciais anafóricos e retextualização, centra-se na percepção do deslocamento de objetos de discurso 
de um gênero textual para outro, no estabelecimento de uma relação anafórica intertextual. Contudo, isso não esgota outras análises em textos do mesmo gênero ou da mesma modalidade. Assim, nosso foco é observar que, quando retextualizamos, valemo-nos de processos referenciais para a (re)construção de referentes, que passam do texto-base para o texto-alvo. Ou seja, construímos anáforas intertextuais.

Nessa perspectiva, baseamo-nos na ancoragem inerente aos princípios fundamentais da referenciação para o desenvolvimento dessa estratégia de transformação textual. Segundo Cavalcante, Custódio Filho e Brito (2014), o fenômeno de construção de objetos de discurso está pautado na instabilidade que permeia os referentes nos mais diversos contextos comunicativos, algo que possibilita a negociação de sentidos entre os interlocutores, com base na natureza sociocognitiva que sustenta a categorização e/ou recategorização da referência.

Nessa esteira, as atividades de retextualização dialogam com as ideias relacionadas à instabilidade dos referentes, à negociação de sentidos e à natureza sociocognitiva, porque a autonomia para a produção escrita dos alunos promove a diversidade de formas de abordagem textual no tocante a determinado referente. Destaca-se, também, a perspectiva interativa que permeia os dois processos e concorre para a construção textual de sentidos a partir de um trabalho de recontextualização.

Da mesma forma, o trabalho com a compreensão textual permite a negociação dos sentidos entre estes interlocutores que ativam sua memória discursiva para categorizar e recategorizar o objeto de discurso, com base em seu conhecimento enciclopédico. Assim,

os processos de referenciação são escolhas do sujeito em função de um querer-dizer. Os objetos-de-discurso não se confundem com a realidade extralinguística, mas (re)constroem-na no próprio processo de interação. (KOCH, 2009, p. 61)

Por isso, ressaltamos que o trabalho de (re)construção dos objetos de discurso, na produção escrita dos alunos, não consiste apenas na reescrita desses referentes encontrados na materialidade linguística do texto-base, mas na 
reelaboração do seu sentido, com ampliação e adequação para outro contexto e para outro cotexto, conforme já adiantamos.

Após essas considerações, a análise aqui proposta diz respeito à transformação textual na passagem do gênero conto para o gênero notícia, e a passagem do gênero poema também para o gênero notícia. A seguir, apresentamos os textos 1 e 2, texto-base e texto-alvo, respectivamente, seguidos da discussão acerca das estratégias de construção de referentes e de retextualização na perspectiva que adotamos, e os textos 3 e 4, na mesma ordem de apresentação e discussão.

\section{Quadro 2 - Texto 1: Conto "Sobressalto" (texto-base para o processo de retextualização)}

É noite quente, de lua clara. As crianças brincam na pequena praça, correndo para lá e
para cá, brincando de pega-pega ou de esconde-esconde, enquanto os pais conversam
animados. Não há o que temer, todos se conhecem. Ali, o tempo corre sem grandes
sobressaltos. As portas e janelas não são trancadas, travas para quê?? A vida moderna e seus
estorvos são vistos de muito longe, esporadicamente. Curiosidade em vivê-la? Não. O que
precisam, eles têm, quase tudo. Um ou dois mascates trazem o que não produzem. Não há o que temer.

Julião Mascate chegou logo cedo à pequena cidade, tocando a buzina para se anunciar: vinha carregado de tecidos coloridos e outras quinquilharias.

- Biiiiippppp!!Bibipiiiiiiii! - É hora, minha senhora! Venha escolher seu tecido! Julião tem de tudo: tem brincos, tem colares. Água de cheiro tem, também! Venha logo. Não demore! - Biiiipppp! Biiiipppp! - Pro patrão, tem também! Para a criançada, bolas coloridas e bonecas, lápis de cor e peteca!

Minutos depois, lá estava Julião, barraca montada na praça. Em dias de barraca na praça, que mal havia de se esquecer de alguns afazeres? As pessoas acorriam, ninguém ficava em casa. Ao entardecer, como sempre, Julião partiria.

Naquela noite, a conversa girava em torno da chegada do mascate e das compras feitas. Lindaura e Alzirinha jogavam peteca, separadas dos demais meninos e meninas.

As vendas foram fracas e, por isso, Julião resolveu ficar na cidadezinha e montar sua barraca novamente no dia seguinte.

A peteca foi arremessada com muita força. Onde foi parar? Lindaura sai à procura do brinquedo. Demora demais. Alzirinha resolveu procurar também. Atrás do coreto, tropeçou e caiu. Caiu sobre o corpo sem vida de Lindaura.

A cidadezinha, tomada de pesar, ficou muda de terror e espanto. Julião Mascate sumiu.

A maldade tomou forma e tocou a todos. Era concreta e tinha nome: Julião Mascate.

Portas e janelas se fecharam. Na praça, não se ouve mais o alarido alegre do riso das crianças, brincadeiras não há. As rodas de conversas diminuíram. Restringem-se a uns poucos homens que conversam baixo e espiam desconfiados por cima do ombro. A cada desconhecido que na cidadezinha chega, um sobressalto. $O$ mal existe. $O$ povo carrega a marca indelével do medo.

Fonte: Martins (2014).

$$
\text { Quadro 3- Texto 2: Notícia (texto-alvo) }
$$

Assassinato assombra cidade do interior do Ceará 


\begin{abstract}
Na noite desta terça-feira (13), um terrível crime aconteceu em uma cidadezinha do interior do Ceará. O corpo da menina Lindaura, de apenas nove anos, foi encontrado por volta das 23h, completamente frio e ensanguentado. O principal suspeito é o camelô conhecido como Julião, que se encontra desaparecido desde o ocorrido. O motivo do crime ainda é um mistério e a família quer justiça. Mas, enquanto esperam, portas e janelas se mantêm fechadas.
\end{abstract}

Fonte: Texto produzido por aluno.

Um ponto inicial da observação, que vale também para o outro par de textos que analisaremos, diz respeito ao aspecto da recontextualização inerente, tanto à forma textual de um e de outro texto quanto ao que consiste no propósito comunicativo do texto-alvo. Com base nisso, ficam claros os ajustes relativos à transformação textual realizada pelo aluno retextualizador, com vistas a contemplar a função comunicativa do texto produzido a partir do texto-base. Desse modo, percebemos, entre outros fatores, a organização textual da notícia com os elementos que a caracterizam dessa forma, como as questões centrais que norteiam o leitor desse gênero, quais sejam: Quem? Quando? Onde? O quê? Como? Por quê?

No tocante à construção dos processos referenciais, entendemos que é perceptível a referenciação intertextual a partir da retomada dos referentes do conto na produção da notícia. Para analisar essa constatação, destacamos algumas palavras e expressões do texto-alvo que estão pautadas em dois referentes do texto-base: a morte de Lindaura e Julião Mascate. Embora a morte da menina não seja apresentada explicitamente como um assassinato, há pistas cotextuais que indicam tal ocorrência, algo que é recategorizado já no título da notícia produzida como Assassinato. Portanto, a escolha lexical em questão determina o posicionamento do redator em relação ao episódio, sendo a morte da criança causada por um crime.

A recategorização presente no título da notícia ativa um referente que é retomado ao longo da construção textual pela expressão nominal indefinida um terrível crime, que chama a atenção para o tópico seguinte do texto, que trata do corpo de Lindaura, que fora encontrado frio e ensanguentado. Assim, podemos dizer que há a construção de um modelo cognitivo em que o episódio é apresentado dessa forma, por se tratar de algo ocorrido em uma cidade pequena e pelo fato de a vítima ser uma criança de apenas nove anos. Esses aspectos contribuem para a caracterização do acontecimento como terrível crime. 
Do ponto de vista da organização textual, essa continuidade possibilitada pela expressão nos mostra que há a retomada de um termo antecedente, mas também há a função prospectiva, visto que age cataforicamente no discurso. Assim, um terrível crime direciona o leitor para o fato posterior, já mencionado acima.

No decorrer do texto, ainda temos a retomada do referente pela escolha lexical crime, além do rótulo ocorrido. Isso posto, e com base em Koch e Elias (2017), fica perceptível o estabelecimento de uma cadeia referencial que contribui para a construção da argumentação apresentada, pois a morte da menina é recategorizada como sendo um assassinato, como podemos observar no título da notícia, algo possível mediante as pistas textuais presentes no texto-base. Nesse sentido, as construções anafóricas posteriores indicam ao leitor a ideia de crime e constituem o fio condutor da argumentação proposta pelo autor.

O referente Julião Mascate, por sua vez, é apresentado mediante a retomada em relação ao conto, inicialmente pela expressão principal suspeito. Tal recategorização de Julião Mascate é oriunda dos elementos linguísticos do conto, que indicam a possibilidade de ele ter cometido o crime pelo fato de ter sumido após a morte da menina, conforme aponta o termo desaparecido.

Chamamos a atenção, também, para o termo anafórico camelô, que se refere à profissão de Julião. Por meio da ativação do conhecimento enciclopédico do produtor do texto, se estabelece a relação de sinonímia apresentada na notícia, tendo em vista que a palavra mascate não faz parte do léxico dos discentes, tendo sido necessária a discussão acerca do vocábulo para dirimir as lacunas de compreensão.

Salientamos que as construções referenciais realizadas pelo produtor do texto-alvo são baseadas em aspectos textual-discursivos e aspectos cognitivodiscursivos que, conforme apontam Lima e Cavalcante (2015), são as duas perspectivas que direcionam a recategorização dos referentes em um texto, que ocorrem tanto pelas pistas textuais, como pelo conhecimento de mundo e de outros aspectos cognitivos.

Apesar de haver margem para a análise de outros referentes, acreditamos que essa breve exposição indica a relevância desses recursos anafóricos para a 
tessitura do texto. Algo parecido ocorre na relação anafórica intertextual entre os textos 3 e 4.

\section{Quadro 4 - Texto 3: Poema (texto-base para a retextualização)}

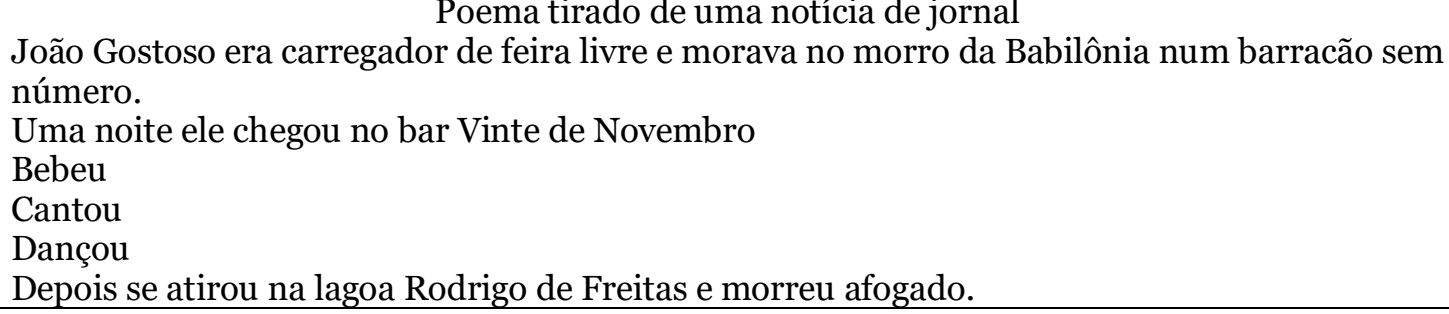

$$
\text { Quadro 5- Texto 4: Notícia (texto-alvo) }
$$

Homem morre afogado em açude
Foi encontrado hoje (21) por volta das sete e quinze, no açude Canoas, localizado na
zona rural de Assaré (CE), o corpo de João Gonçalves Almeida (45), conhecido como “João
Gostoso". Moradores do bairro Alto afirmaram que o entregador de feira-livre tinha começado
a beber com frequência desde que foi deixado por sua mulher, seis meses atrás. A informação
que recebemos é que o bar no qual ele costumava beber e foi visto pela última vez, fechou em
memória do falecido. O dono, Agemiro, e todos da vizinhança prestarão suas homenagens por
volta das 17h do dia de hoje.

Fonte: Texto produzido por aluno.

No texto 4, tomamos para análise o referente João Gostoso, presente no poema e reconstruído na notícia. É possível ver que a cadeia referencial é ancorada nesse objeto de discurso, o qual é apresentado de modo genérico no título, mediante o termo Homem, e especificado no início do texto como João Gonçalves Almeida.

Subsidiados pela proposta classificatória de Cavalcante (2003), podemos dizer que há, no texto-alvo, anáforas com retomada, como é o caso de João Gostoso e João Gonçalves Almeida. O uso do pronome pessoal ele consiste em uma anáfora não co-significativa e não recategorizadora. Temos, ainda, o termo falecido, que rotula o referente em análise, ancorado no sintagma o corpo de João Gonçalves Almeida. Ressaltamos que essas construções anafóricas são realizadas com base no que se apresentou no texto-base, ancorando a produção de sentidos por parte do retextualizador e marcando a relação intertextual. 
Assim como ocorre no primeiro processo de retextualização apresentado, temos no texto 4 a manutenção de um objeto de discurso com sua ampliação e adequação ao contexto que se instaura com o novo gênero. Portanto, a construção textual de sentido com base em um texto âncora concorre para a produção escrita arquitetada por meio de um processo referencial anafórico intertextual.

Salientamos, ainda, a recategorização de referentes do texto-base com a inserção de expressões referenciais pautadas no conhecimento enciclopédico dos alunos, como é o caso da menção ao açude Canoas, que substitui Lagoa Rodrigo de Freitas, citada no poema. Esse tipo de substituição reforça a ideia de recontextualização presente no processo de transformação textual.

A análise dos dois textos-alvo permite concluir que a construção de processos anafóricos contribui para o desenvolvimento das ideias pretendidas pelos autores desses textos, orientando o leitor para a percepção dos sentidos, bem como para a observância da argumentação proposta. Vale dizer que as construções referenciais observadas nos textos-alvo se devem às informações processadas nos textos-base correspondentes para cada processo de retextualização. Assim, podemos concluir, por exemplo, que a menção ao episódio da morte de Lindaura como sendo um assassinato, conforme relatado na notícia, só é possível pelo estabelecimento de uma relação de sentidos entre os dois textos.

Por isso, consideramos que, em ambos os processos de retextualização apresentados, temos a caracterização das anáforas intertextuais, isto é, a transposição de referentes de uma materialidade linguística para outra. Essa abordagem vai além da ideia de análise dos objetos do discurso em uma materialidade linguística apenas.

Destacamos, finalmente, que a construção dos objetos de discurso presentes nos textos, bem como a produção de sentidos observada, apesar de ser resultado de uma proposição didática, aponta para aspectos da realidade desses sujeitos enquanto seres comunicativos. Assim, ainda que não tenhamos uma situação real de comunicação, há a utilização de recursos que caracterizam os processos referenciais anafóricos intertextuais que defendemos nesta discussão. 


\section{Considerações finais}

Como buscamos demonstrar, há um campo de abordagem que pode ser fértil para o estudo das anáforas intertextuais e para a ampliação do horizonte de análise da referenciação - que já é bastante extenso -, bem como para a diversificação dos insumos oferecidos por esse fenômeno para a construção textual de sentidos. Nessa empreitada, também vemos a retextualização como uma estratégia de grande valia para o trabalho com textos escritos, traduzindo-se em uma ferramenta didática que pode ser viabilizada com a exploração de recursos referenciais na perspectiva do ensino. Todavia, não percebemos, até o momento, uma análise mais profunda das anáforas na perspectiva intertextual ou em uma perspectiva de ensino e como subsídio para o desenvolvimento de processos de retextualização.

Diante disso, entendemos que nossa proposta de abordagem apresenta possibilidades de trabalho com textos, sobretudo no tocante à produção escrita, a partir da interface entre os processos referenciais e o desenvolvimento de atividades de retextualização. Dessa maneira, a contribuição deste artigo consiste na possibilidade de trabalho com essas duas estratégias textuais na perspectiva do ensino, bem como no fomento da discussão acerca da agenda das anáforas intertextuais, tendo em vista que a pauta mais comum diz respeito ao caráter intratextual dos processos anafóricos. Vale ressaltar que outros aspectos podem ser observados mediante a proposição de atividades que conjuguem as duas estratégias. Um exemplo disso seria o caso dos dêiticos, recursos referenciais dos quais não tratamos aqui.

Portanto, esperamos ver florescer, no campo da referenciação, mais trabalhos voltados para a análise das anáforas intertextuais e para outros aspectos referenciais na perspectiva intertextual, pois acreditamos que isso é importante, principalmente quando associado ao desenvolvimento da retextualização para o trabalho com produção de textos. 


\section{Referências}

APOTHÉLOZ, Denis. Papel e funcionamento da anáfora na dinâmica textual. Tradução de Mônica Magalhães Cavalcante. In: CAVALCANTE, Mônica Magalhães; BIASE-RODRIGUES, Bernardete; CIULLA, Alena. Referenciação. São Paulo: Contexto, 2003. p. 53-84.

BANDEIRA, Manuel. Estrela da vida inteira: poesias reunidas. Rio de Janeiro/São Paulo: Nova Fronteira, 2007.

BARBOSA, Maria Lourdilene Vieira. A recategorização na retextualização de textos-fonte para a construção de notícias. Revista Escrita, n. 19, p. 1-16, 2014.

CAVALCANTE, Mônica Magalhães. Expressões Referenciais - uma proposta classificatória. Caderno de Estudos Linguísticos, Campinas, v. 44, p. 105-118, jan./jun. 2003.

CAVALCANTE, Mônica Magalhães; CUSTÓDIO FILHO, Valdinar. Revisitando o estatuto do texto. Revista do GELNE, Piauí, v. 12, n. 2, p. 56-71, 2010.

CAVALCANTE, Mônica Magalhães; CUSTÓDIO FILHO, Valdinar; BRITO, Mariza Angélica Paiva. Coerência, referenciação e ensino. São Paulo: Cortez, 2014 .

COELHO, Glaucimere Patero. Retextualização e referenciação: uma análise do objeto-de-discurso em Romeu e Julieta de Shakespeare e nos quadrinhos de Maurício de Sousa. 2013. Dissertação (Mestrado em Estudos Linguísticos) Centro de Ciências Humanas e Naturais, Universidade Federal do Espírito Santo, Vitória, 2013.

CORTEZ, Suzy Leite; KOCH, Ingedore Grunfeld Villaça. A construção do ponto de vista por meio de formas referenciais. In: CAVALCANTE, Mônica Magalhães; LIMA, Silvana Maria Calixto de. Referenciação: teoria e prática. São Paulo: Cortez, 2013. p. 9-29.

CUSTÓDIO FILHO, Valdinar. Referenciação intertextual: análise da construção de objetos de discurso em narrativas com episódios. ReVEL, v. 13, n. 25, 2015.

DELL'ISOLA, Regina Lúcia Péret. Retextualização de gêneros escritos. Rio de Janeiro: Lucerna, 2007.

KOCH, Ingedore Grunfeld Villaça. A referenciação como atividade cognitivodiscursiva e interacional. Caderno de Estudo Linguísticos, Campinas, v. 41, p. 75-89, jul./dez. 2001. 
KOCH, Ingedore Grunfeld Villaça. Introdução à linguística textual: trajetória e grandes temas. 2. ed. São Paulo: Martins Fontes, 2009.

KOCH, Ingedore Grunfeld Villaça. O texto e a construção dos sentidos. 9. ed. São Paulo: Contexto, 2010.

KOCH, Ingedore Grunfeld Villaça; ELIAS, Vanda Maria. Ler e escrever: estratégias de produção textual. 2. ed. São Paulo: Contexto, 2017.

LIMA, Silvana Maria Calixto de; CAVALCANTE, Mônica Magalhães. Revisitando os parâmetros do processo de recategorização. ReVEL, v. 13, n. 25, p. 295-315, 2015.

MARCUSCHI, Luiz Antônio. Da fala para a escrita: atividades de retextualização. São Paulo: Cortez, 2001.

MARCUSCHI, Luiz Antônio. Produção textual, análise de gêneros e compreensão. São Paulo: Parábola Editorial, 2008.

MARTINS, Odenilde Nogueira. Sobressalto. Ode Martins, 2014. Disponível em: http://odemartins.blogspot.com/2014/03/sobressalto-conto-odenilde-n-mar tins.html Acesso em: 16 ago. 2020.

MATA, Maria Aparecida da. Processos referenciais na retextualização de textos acadêmicos. Tese (Doutorado em Estudos Linguísticos) - Faculdade de Letras, Universidade Federal de Minas Gerais, Belo Horizonte, 2008.

MONDADA, Lorena; DUBOIS, Danièlle. Construção dos objetos de discurso e categorização: uma abordagem dos processos de referenciação. Tradução de Mônica Magalhães Cavalcante. In: CAVALCANTE, Mônica Magalhães; BIASERODRIGUES, Bernardete; CIULA, Alena. Referenciação. São Paulo: Contexto, 2003. p. 17-52.

TRAVAGLIA, Luiz Carlos. Fatos pertinentes para o trabalho com a tipologia textual no ensino de língua. In: MARQUESI, Sueli Cristina; PAULIUKONIS, Aparecida Lino; ELIAS, Vanda Maria. Linguística textual e ensino. São Paulo: Contexto, 2017. p. 69-90.

Artigo recebido em 15 de maio de 2020 e aceito em 27 de julho de 2020. 